\title{
Sonographic Measurement of Optic Nerve Sheath Diameter: A Prognostic Tool for Childhood Cerebral Malaria?
}

\author{
Kofi-Mensa Savi de Tové1*, Yolande Savi de Tové-Sissinto², Didier Julien Adedemy ${ }^{3}$, \\ Djivèdé Akanni' ${ }^{1}$, Miralda Kiki ${ }^{1}$, Patricia Yèkpè-Ahouansou ${ }^{4}$, Olivier Biaou ${ }^{4}$, Vicentia Boco ${ }^{4}$, \\ Achille Massougbodji ${ }^{3}$
}

\footnotetext{
${ }^{1}$ Medical Imaging Department, Faculty of Medicine, University of Parakou, Parakou, Republic of Benin

${ }^{2}$ Parasitology Department, Faculty of Health Sciences, University of Abomey Calavi, Cotonou, Republic of Benin

${ }^{3}$ Pediatrics Department, Faculty of Medicine, University of Parakou, Parakou, Republic of Benin

${ }^{4}$ Medical Imaging Department, Faculty of Health Sciences, University of AbomeyCalavi, Cotonou, Republic of Benin

Email: *savitoveto@yahoo.fr
}

How to cite this paper: Savi de Tové, K.-M., de Tové-Sissinto, Y.S., Adedemy, D.J., Akanni, D., Kiki, M., Yèkpè-Ahouansou, P., Biaou, O., Boco, V. and Massougbodji, A. (2019) Sonographic Measurement of Optic Nerve Sheath Diameter: A Prognostic Tool for Childhood Cerebral Malaria? Open Journal of Radiology, 9, 69-81. https://doi.org/10.4236/ojrad.2019.91007

Received: January 30, 2019

Accepted: February 25, 2019

Published: February 28, 2019

Copyright $\odot 2019$ by author(s) and Scientific Research Publishing Inc. This work is licensed under the Creative Commons Attribution International License (CC BY 4.0).

http://creativecommons.org/licenses/by/4.0/ c) (i) Open Access

\begin{abstract}
Background: Childhood cerebral malaria is one of the most frequent complications of malaria, with high morbidity and mortality. Raised Intracranial Pressure (ICP) is currently recognized as a fundamental element of the severity of that disease. This study aims to look into the prognostic role of the sonographic measurement of optic nerve sheath diameter (ONSD) in the context of that disease. Methods: This study was conducted in the pediatric and imaging departments of the University Hospital Center of Parakou in Republic of Benin in West Africa. This was a descriptive cross-sectional study with a prospective data collection conducted over a period of 6 months, from March 1st to August 31st, 2014. There were two groups of children with severe malaria and conscious impairment: one with unrousable coma or Cerebral Malaria (Group 1) and the other without unrousable coma (Group 2), benefitting from ONSD sonographic measurement. ONSD was measured $3 \mathrm{~mm}$ behind the papilla. Correlation between depth of coma, outcome and ONSD measure on ultrasound was investigated. Results: Group 1 consisted of 37 children and Group 2 of 50 children, i.e. a sample of 87 children. The mean age was $27.21 \pm 20.11$ months and sex ratio (Male/Female) estimated at 0.89 . The average ONSD of the sample was $4.39 \pm 0.94 \mathrm{~mm}$ with a significant difference $(\mathrm{p}=0.0001)$ between Group $1(5.09 \pm 1.09 \mathrm{~mm})$ and Group $2(3.87 \pm 0.17$ $\mathrm{mm})$. Raised ICP prevalence was $48.28 \%$ with a significant difference between Group $1(83.78 \%)$ and Group $2(22 \%)$ with $\mathrm{p}<0.0001$. ONSD was higher in children with unfavorable clinical outcome than in those cured $(\mathrm{p}=0.0012)$.
\end{abstract}


Conclusion: Sonographic measurement of ONSD could be a leading prognostic tool in childhood cerebral malaria management.

\section{Keywords}

Cerebral Malaria, Ultrasound, Optic Nerve Sheath Diameter, Prognosis, Correlation

\section{Introduction}

Malaria is a critical public health disease in developing countries. In Africa, one child dies of malaria every minute. In its neurological form due to Plasmodium falciparum, severe malaria is a common cause of death and neurological sequelae in Sub-Saharan Africa [1] [2]. There are two classical forms of severe malaria with conscious impairment i.e. one without unrousable coma and the other with unrousable coma also called "pernicious malaria" or cerebral malaria (CM). The pathophysiology of CM is still poorly clarified. However, several studies demonstrated the presence and the role of raised intracranial pressure (ICP) in the occurrence of deaths and neurological sequelae [3] [4] [5] [6] [7]. The reference method for the diagnosis (gold standard) of raised ICP is continuous measurement of ICP with intraventricular catheter or intraparenchymal sensor. That method is invasive and requires neurosurgical expertise; it also exposes the patient to infectious, mechanical and/or hemorrhagic complications, and is often not available in developing countries [8]. Therefore, the diagnosis of raised ICP mostly relies on clinical examination and optic examination of the eye fundus. Nevertheless, papilledema in case of raised ICP is classically described as late and rarely observed in the infant. The fundus also helps perform the diagnosis of malaria retinopathy, which, according to many authors, would be an important diagnostic and prognostic element of CM [9] [10].

For many years, several authors demonstrated that sonographic measurement of optic nerve sheath diameter (ONSD) is accurate, reproducible and that it helps to diagnose raised ICP [8] [11]-[17]. In addition, this exam, which is affordable, accessible and available in developing countries, allows non-invasive reassessments of ICP. This technique was used in many research works to evidence the raised of ICP during CM, especially in the child [5] [14] [18]. Can the optic nerve sheath diameter measured using ultrasonography be a prognostic tool for children suffering from CM and thus contribute to providing their better care? The aim of this study is to evaluate the possible prognostic role of sonographic measurement of optic nerve sheath diameter for cerebral malaria in children.

\section{Methods}

It was a cross-sectional study with descriptive and analytic purpose conducted 
over a period of six months from March 1 to August 30, 2014. It was conducted in the Borgou Regional University Teaching Hospital (CHDU-B) located in Parakou (Northern Benin). CHDU-B is a second-level referral center, where there are treated patients from all the Northern regions of the country. The study took place in the pediatric unit of that hospital. That unit is a ward of approximately 50 beds and it performs 3500 outpatient consultations and 4000 to 5000 hospitalizations per year.

\subsection{Study Population}

The sample consisted of 87 children suffering from severe malaria with conscious impairment hospitalized in the CHDU-B pediatric unit. Two groups were set up:

- Group 1 consisted of 37 children suffering from severe malaria with unrousable coma or "pernicious malaria" or CM;

- Group 2 consisted of 50 children suffering from severe malaria with conscious impairment but without unrousable coma. We have termed these patients as severe malaria with impaired consciousness.

The sampling was exhaustive, with consecutive selection following the order of admission to the pediatric unit.

A malaria diagnosis was adopted in all cases based on a blood smear containing asexual forms of Plasmodium falciparum.

The diagnosis of $\mathrm{CM}$ is adopted when there was a nonreactive coma i.e. an absence of reaction to nociceptive stimuli (Blantyre coma score $\leq 2$ for children under 5 years; pediatric Glasgow coma score $\leq 9$ for those above 5 years of age). That coma must last more than one hour after the end of a generalized seizure, after the administration of an anti-convulsant treatment, or after the adequate treatment of hypoglycemia. An absence of other etiologies of encephalopathy (metabolic disorders, hypoglycemia, meningitis, meningoencephalitis, severe anemia) in order to adopt that diagnosis [19].

The diagnosis of severe malaria with conscious impairment without unrousable coma (severe malaria with impaired consciousness), was adopted when state of consciousness was altered (pediatric Glasgow coma score $<15$ and $>9$ for children above 5 years of age or Blantyre coma score $<5$ and $>2$ for those under 5 years of age) with one or several signs of neurological severity (repeated convulsions, lethargy, prostration, sign of decerebrate rigidity, sign of decorticate posturing, opisthotonos or other sign) [19]

For treatment, 85 children were treated with quinine salts by intravenous perfusion $(10 \mathrm{mg} / \mathrm{kg} / 8 \mathrm{~h}$ in a serum glucose of $20 \mathrm{ml} / \mathrm{kg}$ in 4 hours every 8 hours till awakening) and 2 children, all in Group 2, were treated with injectable artemisinin derivatives $(4 \mathrm{mg} / \mathrm{kg}$ on the first day and $2 \mathrm{mg} / \mathrm{kg}$ from the second to the 5 th day). All the children benefitted from perfusion of $10 \%$ hypertonic serum glucose. Sixteen children (18.4\%), 5 (13.51\%) from Group 1 and 11 (22\%) from Group 2, received a transfusion of packed red blood cells. All the children from 
Group 1 and 12 children (24\%) from Group 2 were put on oxygen. Two months after the children's discharge a clinical follow-up was done to monitor any sequelae of the illness or treatment.

\subsection{Selection Criteria}

All the children hospitalized for severe malaria with conscious impairment during the study period were involved in the study. The study excluded all children with an obito-ocular disease or any other cause impeding the performance of optic nerve utra-sound, those with a history of psychomotor development disorders or neurological deficits and those with another disease likely to explain altered state of consciousness.

Information was entered based on children's medical record and then transcribed on data collection forms drafted for that purpose. An additional questionnaire for children's parents and/or nursing staff was sometimes necessary. ONSD ultrasound measurements were directly transcribed on those forms.

\subsection{Ultrasound Examination}

An ophthalmic ultrasound with optic nerve measurement was performed among all children involved within a maximum of twelve (12) hours after admission. Examinations were performed using a multi-frequency linear probe $(5-10$ $\mathrm{MHz}$ ) of a Mindray Digi Prince DP 8800 Plus ${ }^{\circledR}$ machine. For ONSD measurement, the child was put in supine position and after applying a gel layer on the upper eyelid, the operator used a linear probe on the latter in the middle position. Two sections (sagittal and transverse) of optic nerve were performed and the ONSD was measured at $3 \mathrm{~mm}$ down the back of the eyeball with the electronic cursors placed on the external limits of the nerve sheath perpendicularly to its axis (Figure 1). We carried out two measurements for each eye: a measure in the transverse plane and a measure in the sagittal plane.

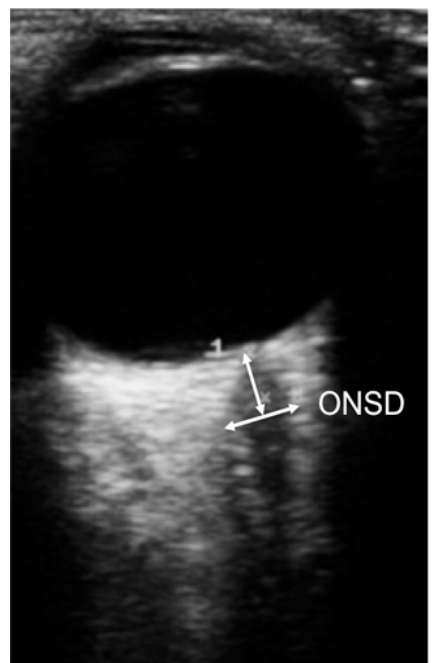

Figure 1. Ultrasound image of the optic nerve (ON) showing the technique of ONSD measurement. 
The older children were required to keep their gaze directed at the zenith, thus enabling positioning of the papilla and the optic nerve in front of the probe. In the cases where children's cooperation could not be obtained, particularly among the youngest ones, the ultrasound probe was handled until an adequate image of the optic nerve was obtained. In those cases, the "loop" (or cinema) mode was used.

The optic nerve is measured three millimeters posterior to the disc (Figure 1) perpendicular to its axis sliders being positioned on the external boundaries of the sheaths.

A patient's ONSD value corresponds to the average of the following four measures:

$$
\begin{gathered}
\text { ONSD }=(\text { RESO + REAO + LESO + LEAO }) / 4 \\
\text { RESO = Right Eye Sagittal ONSD; REAO = Right Eye Axial ONSD } \\
\text { LESO = Left Eye Sagittal ONSD; LEAO = Left Eye Axial ONSD }
\end{gathered}
$$

An ONSD higher than $4 \mathrm{~mm}$ in children under 48 months of age and higher than $4.40 \mathrm{~mm}$ in those older was considered raised and symptomatic of a raised ICP [20].

The study variables were age, sex, optic nerve sheath diameter (ONSD), and altered consciousness. The latter was classified according to pediatric Blantyre or Glasgow coma scores as the case may be. In addition, a study variable was also the clinical outcome of sick children (deaths, recovery with or without sequelae): cured, with sequelae, deceased.

\subsection{Statistical Analyses}

The data collected were entered with Epi data software and processed with STATA software. Fisher's exact test was used to compare the proportions and Kruskal-Wallis non-parametric test to compare the averages. A p-value lower than 0.05 was considered as significant. The correlations were assessed by means of Bravais-Pearson $r$ correlation co-efficient.

This research work got the approval of the local ethics committee and parents of children involved in the study. They were given information in their own language and we got their verbal and sometimes written informed consent.

\section{Results}

During the study period, 597 cases of severe malaria were treated in the CHD-Borgou pediatric unit. Eighty-seven (87) children suffering from severe malaria with conscious impairment were involved in the study. Two groups were formed: Group 1 consisted of 37 children with CM and Group 2 consisted of 50 children without unrousable coma.

\subsection{Age and Sex of the Study Population}

The characteristics of children's age and sex are shown in Table 1. There was no 
Table 1. Children distribution according to sex and age.

\begin{tabular}{cccc}
\hline & Group 1 $(\mathrm{n}=37)$ & Group 2 $(\mathrm{n}=50)$ & Total $(\mathrm{n}=87)$ \\
\hline Age (in month) & & & \\
Mean $\pm \mathrm{SD}^{\mathrm{a}}$ & $34.08 \pm 23.19$ & $22.14 \pm 15.92$ & $27.21 \pm 20.11$ \\
Extremes (min-max) & $(4-96)$ & $(4-84)$ & $(4-96)$ \\
Sex & & & \\
Male (\%) & $14(37.84)$ & $27(54.00)$ & $41(47.13)$ \\
Female (\%) & $23(62.16)$ & $23(46.00)$ & $46(52.87)$ \\
Sex Ratio (M/F) & 0.61 & 1.17 & 0.89 \\
\hline
\end{tabular}

${ }^{\text {a }}$ Standard Deviation.

difference between the two groups $(\mathrm{p}=0.135)$ regarding the sex. Group 1 children were older than the ones from Group $2(\mathrm{p}=0.0149)$.

\subsection{ONSD and Raised ICP Prevalence}

ONSD was accurately measured in all the children involved (see Figure 2).

Table 2 provides a summary of ONSD values of both groups. The ONSD of Group 1 children was significantly higher than the one of Group 2 children (Chi2 $=28.61 ; \mathrm{p}=0.0001)$.

Among the 87 children in the sample, 42 had an ONSD measurement higher than the expected value i.e. a raised ICP of $48.28 \%$. In Group 1, that prevalence was $83.78 \%$ ( 31 children) compared with $22 \%$ (11 children) in Group 2 ( $\mathrm{p}<$ $0.0001)$.

\subsection{ONSD and Age}

Figure 3 shows the distribution of ONSD values according to age in Group 1 ( $\mathrm{r}$ $=0.27$ and $n=37)$ and Figure 4 the one in Group $2(r=0.66$ and $n=50)$.

\subsection{ONSD and Impaired Consciousness}

In our study, we had no case of coma at stage. Table 3 gives a summary of ONSD values in $\mathrm{mm}$ according to depth of coma (stage) in the sample.

\subsection{ONSD and Evolution}

In Group 1, 22 children (59.5\%) were cured without sequelae, 8 (21.6\%) recovered but with sequelae and 7 (18.9\%) died. As sequelae, we observed: muscle contracture in the limbs in 4 cases, loss of ambulation as psychomotor retardation, deafness, aphasia and blindness in each of the cases. There was a difference between the NOSD measures in the different groups of children $(p=0.0014)$. The NOSD measure was smaller for children who recovered without sequelae than for those who had sequelae $(\mathrm{p}=0.023)$ and those who died $(\mathrm{p}=0.002)$. No difference was noted between children with sequelae and those who died $(\mathrm{p}=1)$. Table 4 summarizes the ONSD of children in this group according to evolution. 


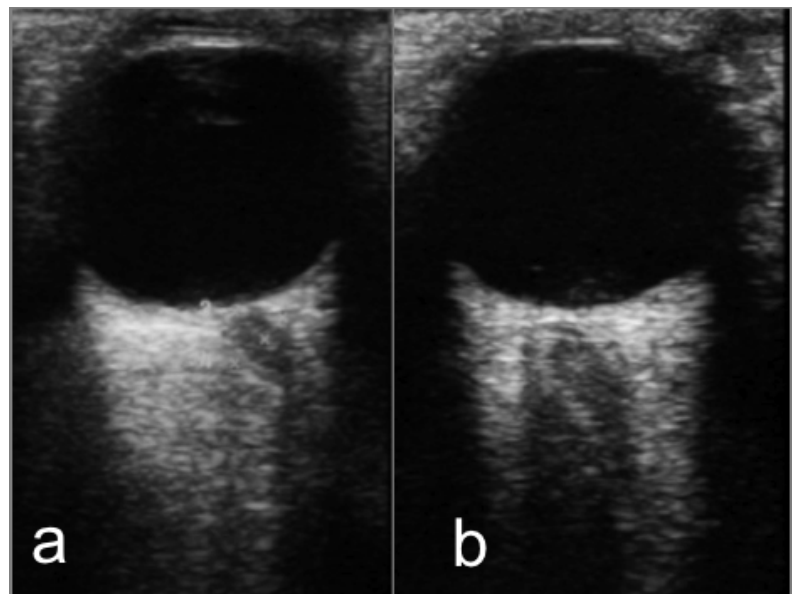

Figure 2. Examples of ultrasound measurements of the optic nerve. (a) Normal diameter optic nerve $(4.02 \mathrm{~mm})$ in a 4 year old child of Group 2; (b) Increased diameter optic nerve $(6.01 \mathrm{~mm})$ in a 4 year old child of Group 1 with an unfavorable course; decease.

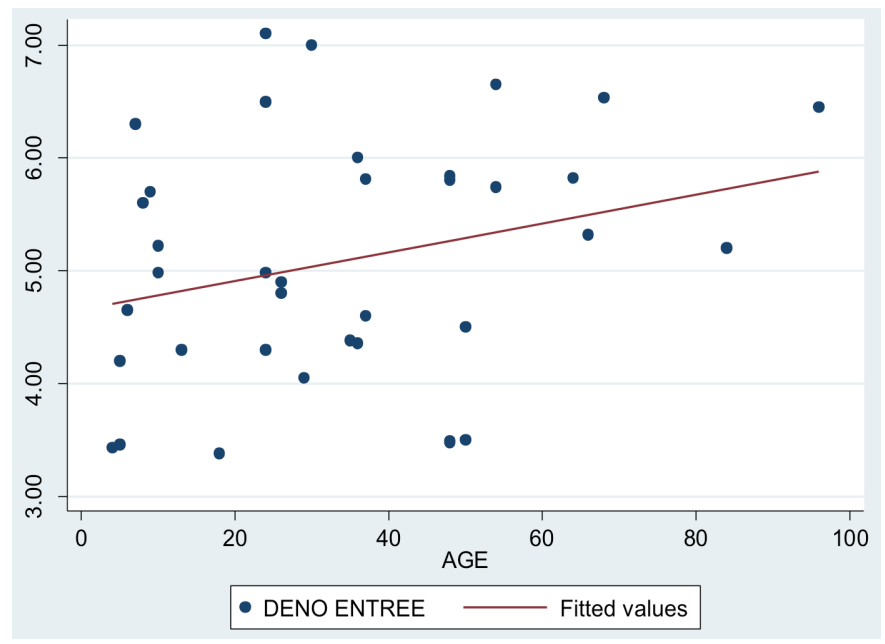

Figure 3. ONSD linear regression line according to age of children in Group $1(\mathrm{CM})$.

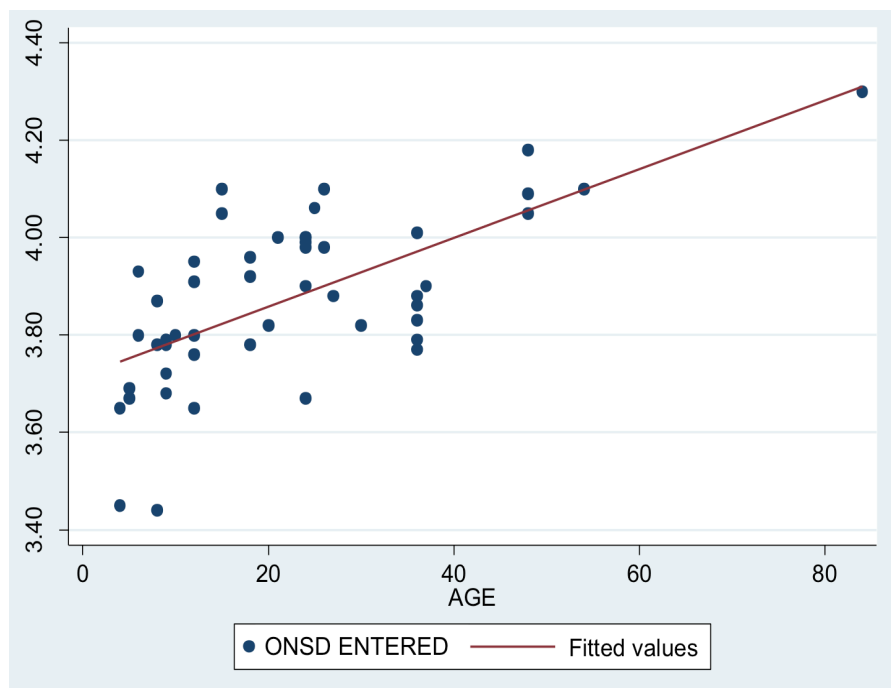

Figure 4. ONSD linear regression line according to age of children from Group 2. 
Table 2. Sample ONSD values in $\mathrm{mm}$.

\begin{tabular}{lccccc}
\hline & Average \pm SD & Min & Max & IC 95\% & p value \\
\hline Group 1 $(\mathrm{n}=37)$ & $5.09 \pm 1.09$ & 3.38 & 7.10 & $4.727-5.453$ & \multirow{2}{*}{0.0001} \\
Group 2 $(\mathrm{n}=50)$ & $3.87 \pm 0.17$ & 3.44 & 4.30 & $3.825-3.922$ & \\
Total $(\mathrm{n}=\mathbf{8 7})$ & $\mathbf{4 . 3 9} \pm \mathbf{0 . 9 4}$ & $\mathbf{3 . 3 8}$ & $\mathbf{7 . 1 0}$ & $\mathbf{4 . 1 9 1 - \mathbf { 4 . 5 9 1 }}$ & \\
\hline
\end{tabular}

${ }^{*}$ Standard Deviation.

Table 3. ONSD values in mm according to depth of coma in the sample.

\begin{tabular}{cccccc}
\hline & Average $\pm \mathrm{SD}^{\mathrm{a}}$ & Min & Max & IC 95\% & p value \\
\hline Stage I $(\mathrm{n}=43)$ & $3.88 \pm 1.79$ & 3.44 & 4.30 & $3.823-3.933$ & \\
Stage II $(\mathrm{n}=35)$ & $4.76 \pm 1.11$ & 3.38 & 7.10 & $4.382-5.146$ & $<0.0001$ \\
Stage III $(\mathrm{n}=9)$ & $5.40 \pm 0.94$ & 3.46 & 6.65 & $4.662-6.115$ & \\
Total $(\mathrm{n}=\mathbf{8 7})$ & $\mathbf{4 . 3 9} \pm \mathbf{0 . 9 4}$ & $\mathbf{3 . 3 8}$ & $\mathbf{7 . 1 0}$ & $\mathbf{4 . 1 9 1 - 4 . 5 9 1}$ & \\
\hline
\end{tabular}

${ }^{a}$ Standard Deviation.

Table 4. ONSD values (in $\mathrm{mm}$ ) according to clinical progression in Group 1.

\begin{tabular}{cccccc}
\hline & Average $\pm \mathrm{SD}^{\mathrm{a}}$ & Min. & Max. & IC 95\%. & p value \\
\hline Recovery without sequelae $(\mathrm{n}=22)$ & $4.58 \pm 0.91$ & 3.38 & 7.00 & $4.172-4.983$ & \\
Recovery with sequelae $(\mathrm{n}=8)$ & $5.96 \pm 1.16$ & 3.48 & 7.10 & $4.996-6.932 \quad \mathrm{p}=\mathbf{0 . 0 0 1 2}$ \\
Deaths $(\mathrm{n}=7)$ & $5.70 \pm 0.45$ & 4.98 & 6.30 & $5.280-6.112$ & \\
Total $(\mathrm{n}=\mathbf{3 7})$ & $\mathbf{5 . 0 9} \pm 1.09$ & $\mathbf{3 . 3 8}$ & $\mathbf{7 . 1 0}$ & $\mathbf{4 . 7 2 7 - 5 . 4 5 3}$ &
\end{tabular}

${ }^{\text {a }}$ Standard Deviation.

In Group 2, 49 children (98\%) had a satisfactory clinical progression, their average ONSD was $3.87 \pm 0.17 \mathrm{~mm}$ with extremes of 3.44 and $4.30 \mathrm{~mm}$. In this group, one child died and his ONSD was $3.91 \mathrm{~mm}(\mathrm{p}=0.7552)$.

\section{Discussion}

In this research work we examined the importance that ONSD sonographic measurement could have as prognostic tool for cerebral malaria (CM). Actually, although patho-physiology is poorly clarified, raised ICP presence during CM had been established by several studies [3] [4] [5] [7] [10] [18] [21]. The severity of that raised ICP would be a critical factor in the prognosis of that disease [7] [21]. Raised ICP diagnostic tools are variable. Cerebro-spinal fluid (CSF) opening pressure is commonly used in the absence of the reference method: continuous measurement of intracranial pressure (ICP) with intraparenchymal sensor or intraventricular catheter. Those two methods are invasive and likely to produce adverse effects [8]. Besides, their availability is limited in countries with few and poor quality health facilities where Plasmodium falciparum malaria is endemic. The first re-search works carried out to point out raised ICP during CM had used CSF opening pressure by lumbar puncture [3] [22]. Then, CT [4] 
[18] [23] and MRI [7] [24] cross-sectional imaging techniques were implemented to identify ICH. Those cross-sectional techniques are expensive and their availability is also limited in countries affected by CM.

Sonographic optic nerve diameter measurement is a relatively recent technique used for raised ICP diagnosis [25] [26]. It is a noninvasive technique, which is available in most of health facilities of developing countries. Many studies [14] [15] [27] [28] [29] [30] had confirmed its reliability and reproducibility in raised ICP assessment. Moreover, several studies had identified ONSD normal values in children [11] [25] [31] [32], including one performed within a population similar to that in this study [20]. Therefore, it is an excellent alternative to the other methods used for raised ICP identification in children with CM in developing countries.

\subsection{Optic Nerve Ultrasound and Raised ICP Prevalence within the Study Population}

In this study, optic nerve ultrasound determined an ONSD average value of 4.39 $\pm 0.94 \mathrm{~mm}$ and identified a raised ICP in $48.28 \%$ of the subjects. This raised ICP prevalence is similar to the one found by Beare et al. in Malawi in 2012 (49\%) within a population of children with severe malaria, all forms combined [5]. A prevalence lower than 33.33\% was identified by Murphy et al. in Uganda in 2011 in children suffering from malaria (uncomplicated forms included) [18].

ONSD average and raised ICP prevalence was higher $(\mathrm{p}<0.0001)$ in Group 1 $(5.09 \pm 1.09 \mathrm{~mm}$ and $83.78 \%)$ than in Group $2(3.87 \pm 0.17 \mathrm{~mm}$ and $22 \%)$. These findings confirm raised ICP role in the severity of neurological disorders in severe malaria with conscious impairment.

Raised ICP role in the disorders of consciousness in severe malaria with conscious impairment affected children is also suggested in this study by the significant increase $(p<0.0001)$ of ONSD average measurement associated with severity of coma (Table 3 ).

\subsection{ONSD and Age}

In healthy children, ONSD raises with age and this growth occurs especially within the first 48 months of life [11] [20] [26]. That correlation continues during severe cerebral malaria without unrousable coma (Group 2) with an average correlation of $\mathrm{r}=0.66$; whereas in the series of children suffering from $\mathrm{CM}$ (Group 1) that correlation between ONSD and age becomes low $(r=0.27)$. This reflects the fact that in children suffering from $\mathrm{CM}$, as clinically defined, raised ICP occurs in varying degrees.

Clinically, raised ICP can also be identified through the presence of papilledema in the fundus. Unfortunately, this is a late onset sign and its reliability is limited. Several research works have noted the absence of correlation between presence of papilledema and an unfavorable clinical progression [7] [33]. However, other studies have demonstrated that the presence of papilledema is highly 
associated with death [34]. Furthermore, papilledema is more common among children with raised ONSD [5]. Papilledema may be associated with the following signs of malaria retinopathy: retinal pallor, vascular changes and retinal hemorrhages. Those malaria retinopathy signs are common and encountered in most cases of CM [35]. In malaria-endemic areas, these are signs that help differentiate comas due to malaria from other etiologies of coma [35] [36]. Besides, in developing countries the most sensitive technique for identifying those signs (indirect ophthalmoscopy) is expensive and its availability is limited [35].

\subsection{ONSD and Outcome}

In our series, the ONSD of children with sequelae or those who died was significantly higher than the one of children who are cured $(\mathrm{p}<0.0001)$. But no difference was noted between the ONSD of deceased children and those of children with sequelae. There are serious reasons to fear adverse clinical progression (sequelae or death) in any child with severe cerebral malaria with an ONSD greater than or equal to $5 \mathrm{~mm}$ (Table 4). Newton et al. had also reported in 1997 that children with a severe raised ICP had more frequent sequelae [21]. In 2012, while concluding their research work conducted on CM, Beare et al. also reported a significantly raised ONSD identified in children discharged with sequelae compared to children who recovered [5].

\section{Conclusion}

Sonographic measurement of ONSD, a technique available in developing countries, could be a leading prognostic tool in the management of childhood CM. In this study, children who died or had sequelae had a higher ONSD than the others. An ONSD greater than or equal to $5 \mathrm{~mm}$ can be considered as a factor of poor prognosis in child suffering from CM.

\section{Conflicts of Interest}

The authors declare no conflicts of interest regarding the publication of this paper.

\section{References}

[1] Idro, R., Ndiritu, M., Ogutu, B., Mithwani, S., Maitland, K., Berkley, J.A., et al. (2007) Burden, Features and Outcome of Neurological Involvement in Acute Falciparum Malaria in Kenyan Children. JAMA, 297, 2232-2240. https://doi.org/10.1001/jama.297.20.2232

[2] John, C.C., Bangirana, P., Byarugaba, J., Opoka, R.O., Idro, R., Jurek, A.M., et al. (2014) Cerebral Malaria in Children Is Associated with Long-Term Cognitive Impairment. Pediatrics, 122, e92-e99. https://doi.org/10.1542/peds.2007-3709

[3] Newton, C.R.J.C., Winstanley, P.A., Peshu, N., Marsh, K., Kirkham, F.J., Pasvol, G., et al. (1991) Intracranial Pressure in African Children with Cerebral Malaria. Lancet, 2, 573-576. https://doi.org/10.1016/0140-6736(91)91638-B

[4] Newton, C.R.J.C., Peshu, N., Kendall, B., Kirkham, F.J., Sowunmi, A., Waruiru, C., 
et al. (1994) Brain Swelling and Ischaemia in Kenyans with Cerebral Malaria. Archives Disease Child, 70, 281-287. https://doi.org/10.1136/adc.70.4.281

[5] Beare, N.A.V., Glover, S.J., Lewallen, S., Taylor, T.E., Harding, S.P. and Molyneux, M.E. (2012) Prevalence of Raised Intracranial Pressure in Cerebral Malaria Detected By Optic Nerve Sheath Ultra-Sound. American Journal of Tropical Medicine and Hygiene, 87, 985-988. https://doi.org/10.4269/ajtmh.2012.11-0459

[6] Frevert, U. and Nacer, A. (2014) Fatal Cerebral Malaria: A Venous Efflux Problem. Frontiers in Cellular and Infection Microbiology, 4, 155. https://doi.org/10.3389/fcimb.2014.00155

[7] Seydel, K.B., Kampondeni, S.D., Valim, C., Potchen, M.J., Milner, D.A., Muwalo, F.W., et al. (2015) Brain Swelling and Death in Children with Cerebral Malaria. The New England Journal of Medicine, 19, 1126-1137. https://doi.org/10.1056/NEJMoa1400116

[8] Wiegand, C. and Richards, P. (2007) Review Measurement of Intracranial Pressure in Children: A Critical Review of Current Methods. Developmental Medicine and Child Neurology, 49, 935-941. https://doi.org/10.1111/j.1469-8749.2007.00935.x

[9] Beare, N., Southern, C., Chalira, C., Taylor, T., Molyneux, M. and Harding, S. (2004) Prognostic Significance and Course of Retinopathy in Children with Severe Malaria. Archives of Ophtalmology, 122, 1141-1147. https://doi.org/10.1001/archopht.122.8.1141

[10] Potchen, M.J., Kampondeni, S.D., Seydel, K.B., Birbeck, G.L., Hammond, C.A., Bradley, W.G., et al. (2012) Acute Brain MRI Findings in 120 Malawian Children with Cerebral Malaria: New In-Sights into an Ancient Disease. American Journal of Neuroradiology, 33, 1740-1746. https://doi.org/10.3174/ajnr.A3035

[11] Malayeri, A.A., Bavarian, S. and Mehdizadeh, M. (2005) Sonographic Evaluation of Optic Nerve Diameter in Children with Raised Intracranial Pressure. Journal of UItrasound in Medicine, 24, 143-147. https://doi.org/10.7863/jum.2005.24.2.143

[12] Tayal, V.S., Norton, H.J., Foster, T. and Saunders, T. (2007) Sonographic Measurement of Optic Nerve Sheath Diameter to Detect Findings of Increased Intracranial Pressure in Adult Head Injury Patients. Annals of Emmergency Medicine, 49, 508-514. https://doi.org/10.1016/j.annemergmed.2006.06.040

[13] Girisgin, A.S., Kalkan, E., Kocak, S., Cander, B., Gul, M. and Semiz, M. (2007) The Role of Optic Nerve Ultrasonography in the Diagnosis of Elevated Intracranial Pressure. Emergency Medicine Journal, 24, 251-254. https://doi.org/10.1136/emj.2006.040931

[14] Beare, N.A.V., Kampondeni, S., Glover, S.J., Molyneux, E., Taylor, T.E., Harding, S.P., et al. (2008) Detection of Raised Intracranial Pressure by Ultrasound Measurement of Optic Nerve Sheath Diameter in African Children. Tropical Medicine and International Health, 13, 1400-1404. https://doi.org/10.1111/j.1365-3156.2008.02153.x

[15] Kimberly, H.H., Shah, S., Marill, K. and Noble, V. (2008) Correlation of Optic Nerve Sheath Diameter with Direct Measurement of Intracranial Pressure. Academic Emergency Medicine, 15, 201-204. https://doi.org/10.1111/j.1553-2712.2007.00031.x

[16] Le, A., Hoehn, M.E., Smith, M.E., Spentzas, T. and Schalappy, D. (2009) Bedside Sonographic Measurement of Optic Nerve Sheath Diameter as a Predictor of Increased Intracranial Pressure in Children. Annals of Emergency Medicine, 53, 785-791. https://doi.org/10.1016/j.annemergmed.2008.11.025

[17] Qayyum, H. and Ramlakhan, S. (2013) Can Ocular Ultrasound Predict Intracranial 
Hypertension? A Pilot Diagnostic Accuracy Evaluation in a UK Emergency Department. European Journal of Emergency Medicine, 20, 91-97. https://doi.org/10.1097/MEJ.0b013e32835105c8

[18] Murphy, S., Cserti-Gazdewich, C., Dhabangi, A., Musoke, C., Nabukeera-Barungi, N., Price, D., et al. (2011) Ultrasound Findings in Plasmodium falciparum Malaria: A Pilot Study. Pediatric Critical Care Medicine, 12, e58-e63. https://doi.org/10.1097/PCC.0b013e3181e89992

[19] World Health Organization (2000) Severe Falciparum Malaria. Transactions of the Royal Society of Tropical Medicine and Hygiene, 94, 1-90. https://doi.org/10.1016/S0035-9203(00)90300-6

[20] Savi de Tové, K.M., Biaou, O., Adedemy, J.D., Fatigba, O.H., Yèkpè, P., Boco, V., et al. (2014) So-Nographic Evaluation of Optic Nerve Sheath Diameter in the Healthy Black African Child. Pan African Medical Journal, 19, 285.

[21] Newton, C.R.J.C., Crawley, J., Sowumni, A., Waruiru, C., Mwangi, I., English, M., et al. (1997) Intra-Cranial Hypertension in Africans with Cerebral Malaria. Archives of Disease in Childhood, 76, 219-226. https://doi.org/10.1136/adc.76.3.219

[22] Waller, D., Crawley, J., Nosten, F., Chapman, D., Krishna, S., Craddock, C., et al. (1991) Intracranial Pressure in Childhood Cerebral Malaria. Transactions of the Royal Society of Tropical Medicine and Hygiene, 85, 362-364. https://doi.org/10.1016/0035-9203(91)90291-6

[23] Maude, R.J., Barkhof, F., Hassan, M.U., Ghose, A., Hossain, A., Abul Faiz, M., et al. (2014) Magnetic Resonance Imaging of the Brain in Adults with Severe Falciparum Malaria. Malaria Journal, 13, 177. https://doi.org/10.1186/1475-2875-13-177

[24] Potchen, M.J., Birbeck, G.L., DeMarco, J.K., Kampondeni, S.D., Beare, N., Molyneux, M.E., et al. (2010) Neuroimaging Findings in Children with Retinopathy-Confirmed Cerebral Malaria. European Journal of Radiology, 74, 262-268. https://doi.org/10.1016/j.ejrad.2009.02.010

[25] Helmke, K. and Hansen, H.C. (1996) Fundamentals of Transorbital Sonographic Evaluation of Optic Nerve Sheath Expansion under Intracranial Hypertension I Experimental Study. Pediatrics Radiology, 26, 701-705. https://doi.org/10.1007/BF01383383

[26] Hansen, H.C. and Helmke, K. (1997) Validation of the Optic Nerve Sheath Response to Changing Cerebrospinal Fluid Pressure: Ultrasound Findings during Intrathecal Infusion Tests. Journal of Neurosurgery, 87, 34-40. https://doi.org/10.3171/jns.1997.87.1.0034

[27] Steinborn, M., Fiegler, J., Ruedisser, K., Hapfelmeier, A., Denne, C., Macdonald, E., et al. (2011) Measurement of the Optic Nerve Sheath Diameter in Children: Comparison between Trans-Bulbar Sonography and Magnetic Resonance Imaging. UItraschall in der Medizin, 33. https://doi.org/10.1055/s-0031-1273491

[28] Rajajee, V., Vanaman, M., Fletcher, J.J. and Jacobs, T.L. (2011) Optic Nerve Ultrasound for the Detection of Raised Intracranial Pressure. Neurocritical Care, 15, 506-515. https://doi.org/10.1007/s12028-011-9606-8

[29] Bäuerle, J., Schuchardt, F., Schroeder, L., Egger, K., Weigel, M. and Harloff, A. (2013) Reproducibility and Accuracy of Optic Nerve Sheath Diameter Assessment Using Ultrasound Compared to Magnetic Resonance Imaging. BMC Neurology, 13, 187. https://doi.org/10.1186/1471-2377-13-187

[30] Amini, A., Eghtesadi, R., Zeizi, A.M., Mansouri, B., Kariman, H., Dolatabadi, A.A., et al. (2013) Sonographic Optic Nerve Sheath Diameter as a Screening Tool for Detection of Elevated Intra-Cranial Pressure. Emergency, 1, 15-19. 
[31] Ballantyne, J., Hollman, A.S., Hamilton, R., Bradnam, M.S., Carachis, R., Young, D.G., et al. (1999) Optic Nerve Sheath Ultrasonography Normal Children. Clinical Radiology, 54, 740-742. https://doi.org/10.1016/S0009-9260(99)91176-5

[32] Körber, F., Scharf, M., Moritz, J., Dralle, D. and Alzen, G. (2005) Sonography of the Optical Nerve-Experience in 483 Children. RöFo, 177, 229-235. https://doi.org/10.1055/s-2004-813936

[33] Kampondeni, S.D., Potchen, M.J., Beare, N.V., Seydel, K.B., Glover, S.J., Taylor, T.E., et al. (2013) MRI Findings in a Cohort of Brain Injured Survivors of Pediatric Cerebral Malaria. The American Journal of Tropical Medicine and Hygiene, 88, 542-546. https://doi.org/10.4269/ajtmh.12-0538

[34] Smith, A., Beare, N.A.V., Musumba, C.O. and Lochhead, J. (2013) New Classification of Acute Papilledema in Children with Severe Malaria. Journal of Pediatric Neurology, 7, 381-388.

[35] Beare, N.A., Lewallen, S., Taylor, T.E. and Molyneux, M.E. (2011) Redefining Cerebral Malaria by Including Malaria Retinopathy. Future Microbiology, 6, 349-355. https://doi.org/10.2217/fmb.11.3

[36] Lewallen, S., Bronzan, R.N., Beare, N.A., Harding, S.P., Molyneux, M.E. and Taylor, T.E. (2008) Using Malaria Retinopathy to Improve the Classification of Children with Cerebral Malaria. Transactions of the Royal Society of Tropical Medicine and Hygiene, 102, 1089-1094. https://doi.org/10.1016/j.trstmh.2008.06.014 